denominei de 'a longa noite hobbesiana' significaram, cada qual à sua maneira, momentos históricos em que se lançaram as bases para progressos que de outra forma demorariam mais tempo para consolidar-se como realidade e tornar-se coisa comum na consciência coletiva" ( $\mathrm{p}$. XIV).

Coerente até o fim, seu livro conclui com uma ponta confessa de pessimismo. Feridos de morte ou desarticulados o Partido Fardado, a União e a Federação,

[...] sobraram as personalidades, mas não havendo estruturas que impulsionem o processo social, a Política feneceu. O Mercado, novo deus fenício a cobrar sacrifícios, impôs-se como senhor de baraço e cutelo. Como dizia alguém, quando não há política, há pornografia. $\mathrm{Ou}$, parafraseando outrem, aristocrata e mais polido, poderia dizer que, tendo desaparecido a Grande Política, as Idéias, discutem-se as pessoas. Quando possível (p. 591).

Salvo melhor juízo, é precisamente onde nos encontramos. Vinte e dois anos depois da redemocratização, ainda falta ao Brasil a solução de seu enigma fundacional, o da organização autônoma da sociedade, bem como o da reposição em novas e duradouras bases dos elos entre estrutura jurídico-político-administrativa (União, Federação, sistema político) e mundo da vida social, entre Estado e sociedade. Continuamos sem sujeitos capazes de promover "políticas dirigidas para o futuro" e seguramente sem projetos nacionais. Talvez o capitalismo globalizado e informacional, a modernidade líquida e radicalizada que celebra o ingresso dos humanos no século XXI, impeça que se continue a pensar em termos de sujeitos e projetos nacionais. Esta é uma questão categoricamente em aberto. Se provocado, Oliveiros Ferreira diria que o momento requer o amadurecimento de novos "revolucionários da Ordem", ao estilo do que imaginaram certas traduções do Partido Fardado. Pode não ser a melhor perspectiva, a via mais plausível e factível, mas não deixa de ser uma perspectiva.

\footnotetext{
MARCO AURÉLIO NOGUEIRA é professor titular de Teoria Política da Faculdade de Ciências e Letras da Universidade Estadual Paulista (Unesp), campus de Araraquara, SP. E-mail: nogueira@fclar.br.
}

\section{A dureza (e a ternura) do essencialismo político}

Armando BOITO Jr. Estado, politica e classes sociais. São Paulo, Edunesp, 2007. 271 páginas.

\section{Cicero Araujo}

Este livro de Armando Boito Jr. deve causar certo desconcerto ao leitor. Embora anuncie, logo no início, que sua "ambição maior" é contribuir para "a renovação da teoria marxista", é um tanto difícil discernir o que há de fato renovador na coletânea de ensaios que reuniu no livro. Não que isso o torne desinteressante: em sua própria reiteração de idéias desgastadas, há algo de engenhoso no texto. O desconcerto talvez seja causado também pelo estilo: fórmulas duras são defendidas com incrível serenidade, que às vezes até deixam escapar locuções do tipo "nos parece que", "não acredito que", "não é nossa convicção" - como se fossem um cumprimento aos leitores indispostos, os quais o autor provavelmente saiba não serão poucos. As críticas que seguem, aliás, não tem pretensão de novidade; no entanto, como o livro não registra sua existência, será preciso insistir nelas aqui.

O volume está dividido em duas partes. A primeira trata de questões abrangentes da teoria política marxista: o Estado, a transição entre tipos de Estado, suas relações com o modo de produção e as classes sociais, as revoluções e o socialismo. A segunda concentra-se no mundo do trabalho, suas mutações (ou não), a organização sindical e política das classes trabalhadoras, o conceito de cidadania nesse contexto e, novamente (mas agora com um olhar para o futuro), o socialismo e a revolução. O pressuposto das duas partes parece ser a idéia de modo de produção como uma totalidade social, "não se atendo, portanto, apenas ao nível econômico". Isso leva o autor a pensar cada modo de produção como composto de dois níveis integrados: de um lado, as forças produtivas e as relações de produção e, de outro, o Estado ("a estrutura jurídico-política"). De forma que, por exemplo, o capitalismo como modo de produção não é apenas a economia, mas o Estado "capitalista" ou "burguês", com ambos os níveis se "determinando" e "sobredeterminando" um ao outro; o mesmo 
vale para o feudalismo, o escravismo antigo etc. Mas "modo de produção", continua o autor, é ainda um conceito genérico, abstraído das especificidades históricas, ao contrário de "formação social", em que tais peculiaridades são resgatadas: um mesmo modo de produção pode abranger diferentes formações sociais (por exemplo, o capitalismo inglês, alemão ou norte-americano).

Como sabemos, e o próprio autor registra, essa idéia já havia sido claramente construída pelo marxismo althusseriano, na década de 1960. Porém, suas conseqüências no plano da teoria política, e especialmente na crítica do "economicismo", teriam ficado à espera de outros desenvolvimentos. Armando Boito Jr. lamenta, nesse sentido, que a obra de N. Poulantzas não tenha alcançado ainda o devido reconhecimento, uma vez que ela se concentra numa dessas importantes conseqüências: o conceito de Estado. Para Poulantzas, o Estado não é um simples reflexo político da dominação de classe no plano econômico. Na verdade, ele organiza, em termos jurídico-políticos, essa dominação. Isto é, para além de pura função defensiva (via aparato repressivo), o Estado cumpre uma "função ideológica", e com isso possibilita que uma classe seja efetivamente dominante, e não apenas uma classe exploradora. "O Estado é o principal fator de coesão das formações sociais divididas em classes, graças à sua função repressiva e a outro aspecto, quase sempre ignorado, que é a sua função ideológica. De um lado, esse organismo detém o monopólio da força organizada [...] De outro lado, o Estado secreta, permenentemente, as figuras ideológicas fundamentais para a reprodução mais ou menos pacífica das relações de produção" (p. 55). Com essa tese, Armando Boito Jr. procura oferecer suas próprias contribuições.

Gostaria de destacar duas delas: sua reinterpretação de "classe social" e o conceito de "cena política". São idéias que poderiam ser consideradas inovadoras, não fossem elas descoloridas pelo modo como o autor as encaixa na tradição revolucionária do marxismo. Embora, obviamente, a noção de classe seja importante em todo livro, é só no início da segunda parte que sua reelaboração aparece com clareza. Boito Jr. generaliza a tese de que uma classe dominante não pode "dominar" sem o Estado. No fundo, nenhuma classe social existe em si mesma, e sua existência real sempre depende da capacidade de se organizar politica- mente. Esse enunciado vale em especial para as classes dominadas, que não têm um Estado a seu serviço, e cuja organização pode compreender diferentes níveis de consciência política, dependendo do grau e da generalidade da resistência/contestação à ordem, isto é, desde a mais incipiente (reivindicativa) até a mais desenvolvida (revolucionária). Importa que, no caso do capitalismo, graças à universalização das relações contratuais no trabalho, essa consciência é inicialmente ativada pela própria estrutura jurídica do Estado. Isso explica por que, sob o Estado burguês, mas não sob os "Estados pré-capitalistas", as classes trabalhadoras puderam se organizar sindicalmente, embora nem sempre - isso dependeria das particularidades de cada formação social - o tenham feito no sentido de formas politicas mais desenvolvidas. Em suma, uma classe social não se define apenas por sua posição na produção ou no mercado econômicos, mas por um conjunto de motivos, entre os quais o tipo de crença social e política a que adere: "O antagonismo entre proprietários e trabalhadores é apenas latente, potencial. Para que a classe operária, que existe apenas em potência no terreno da economia capitalista, adquira uma existência ativa, é necessária a combinação de inúmeros fatores de ordem econômica, política e ideológica" (p. 197). A tese fica muito bem ilustrada na análise que o autor faz do chamado "sindicalismo de classe média", que lhe permite, graças ao fator ideológico, diferenciar esse estrato social das camadas propriamente operárias, não tanto por uma questão econômica, mas pela "ideologia meritocrática".

Essa reelaboração poderia ter rendido questões muito interessantes a respeito das relações entre classes sociais e política, infelizmente pouco estudadas desde que o marxismo perdeu seu ímpeto no interior da ciência política. Porém, a oportunidade é perdida, neste livro, por conta de o autor manter-se rigorosamente preso ao dualismo da aparência/essência, que guia sua noção de "estrutura jurídico-política" e, de resto, todas as noções que conformam o conceito mais amplo de "ideologia". Desse modo, a ideologia é sempre uma "ilusão", ainda que uma ilusão socialmente eficaz. Por que eficaz? Porque, seguindo a fórmula de Althusser, a ideologia é uma "alusão" à realidade, "adere" ao real, tornando-a plausível, ao mesmo tempo em que, por isso mesmo, mascara sua "essência". Polemizando com o conceito de poder de Foucault, 
que a seu ver não dá a devida importância ao Estado como centro da produção e difusão ideológica - crítica que estenderá aos marxistas gramscianos, por deslocarem essa função para a "sociedade civil" -, Boito Jr. argumenta: "É o direito capitalista que, criando a igualdade formal, cria, no trabalhador, a ilusão de que a relação de exploração de seu trabalho é uma relação contratual entre partes livres e iguais [...]. A proclamação da liberdade é, como diria Louis Althusser nos seus comentários sobre a ideologia, uma alusão à realidade. Mas essa mesma proclamação é, também e principalmente, uma ilusão, na medida em que oculta a relação de exploração e de dominação de classe" (p. 28, grifos do autor). Em outras palavras, a ideologia, uma "aparência real" cuja função básica é distorcer e falsear, jamais pode servir para construir positivamente a ação política, como um fator de emancipação social. Ao contrário, é um pressuposto irredutível de sua análise que a ideologia será sempre negativa, completando - e de uma maneira até mais decisiva do que no marxismo tradicional - o sistema de dominação esboçado no nível das relações de produção.

Mas por que tem de ser assim? Como um investigador social pode afirmar com tanta segurança que tem diante de si uma representação ilusória, um "falseamento", uma "ocultação"? É aí que o velho dualismo da aparência/essência cobra o seu preço, não exatamente ao modo de uma metafísica platônica, mas pela postulação de uma Ciência Social capaz de desvelar as "leis" do processo histórico, o que politicamente acaba dando no mesmo. Essa postulação nunca é deixada de lado, por mais que o autor tente moderá-la, ao dizer que a causalidade histórica não é única, mas múltipla, e que portanto não há inevitabilidade nos acontecimentos sociais, mas apenas "possibilidade". Pois ele faz essa concessão menos por razões intrínsecas às práticas científicas do que para combater seus adversários no campo do marxismo entre os quais, especialmente, o "marxismo economicista", que "tende ao reformismo" - e então acentuar a solução "política", a única forma de tornar real aquilo que as "leis" da ciência só estabelecem como possível. Essa última afirmação, que em outro contexto soaria como perfeitamente razoável, apta a sugerir uma concepção falibilista do conhecimento social, não diminui em nada a rígida oposição, nunca posta em questão, entre ideolo- gia e ciência, entre a primeira que falseia, distorce, mascara, e a segunda que está vocacionada para a verdade.

Mas não é óbvio que a ciência social está repleta de concepções contraditórias, divergentes, da própria sociedade e do que, em termos de potencialidade história, venha a reservar para a humanidade? Não há indícios de que o autor não reconheça esse fato, mas isso em nada o leva a pensar num trânsito construtivo entre ciência social e ideologia - e assim desconfiar que suas próprias teses poderiam conter algo da última. Ao contrário, ele tende a endurecer ainda mais a oposição. Havendo algum trânsito entre os dois, isso só poderia ocorrer porque as práticas científicas, elas mesmas, são passíveis de contaminação pelo falseamento ideológico. É claro: a luta de classes não poupa nada e ninguém!

Vejamos agora o conceito de "cena política", que no livro seria um outro bom candidato à renovação desejada por Armando Boito Jr. Contudo, o leitor encontrará nele apenas um reforço das impressões descritas acima. Primeiro porque lança mão, sem nenhuma reserva, do mote ilusionista que um dos significados possíveis de "cena" sugere: não está se falando de um espaço de explícita representação política, mas de disfarce, ou melhor, de uma estranha farsa necessária, dado que a estrutura de classes impede que os interesses representados apareçam claramente na cena, e talvez até mesmo na consciência dos próprios atores, embora, ao fim e ao cabo, são, sim, esses interesses que estão em jogo. "A opacidade da cena política remete à dissimulação e à representação dos interesses de classe, não se circunscrevendo, portanto, ao universo dos interesses dos políticos profissionais [...]. Os indivíduos estão determinados por sua situação de classe e de fração. Fazem escolhas, mas essas escolhas também refletem interesses e condições que, no mais das vezes, eles próprios ignoram" (p. 150). Porém, em segundo lugar, seu dualismo faz Boito Jr. recorrer de novo à idéia de uma ciência autêntica, dessa vez oposta à "ciência vulgar", e capaz de determinar as verdadeiras relações entre representantes e representados: "É a análise científica que pode desvelar a realidade profunda encoberta pela realidade aparente. O observador que se ativer, como o economista vulgar, à esfera da circulação, produzirá idéias superficiais e mistificadoras” (p. 138). Essa crítica não poupa nem mesmo os marxistas: "Praticar 
análise política designando os agentes presentes na cena política pelos nomes e objetivos que eles próprios dão é permanecer na superfície enganosa do fenômeno, e muitos marxistas incorrem nesse erro, típico da ciência política vulgar" (p. 140).

Note-se que o problema desse conceito não é o fato de desconfiar dos "nomes e objetivos" que os próprios agentes se dão: isso é perfeitamente sustentável em qualquer análise política sóbria. $\mathrm{O}$ problema é a polarização fixa, esquemática, entre a aparência e a essência, que torna essa última acessível apenas a certos observadores privilegiados, só eles dotados do instrumental científico digno desse nome, enquanto todos os demais estão condenados não só a incorrer no erro, mas a ser cúmplices do disfarce. Mais do que isso: é um esquema que condena certos atores inevitavelmente ao lado da aparência, e outros, ao da essência. Baseado em que critério? O único a que, supostamente, um discípulo de Marx poderia recorrer: "Marx concebe a cena politica nas sociedades capitalistas, como uma espécie de superestrutura da luta de classes e de frações de classe, que formam aquilo que poderíamos denominar a base socioeconômica da cena política" (p. 139, grifos do autor). Aí está: depois de tantas "sobredeterminações" do político, e tantas outras críticas ao "economicismo", eis que voltamos finalmente à "determinação em última instância". "A cena política é uma realidade superficial, enganosa, que deve ser desmistificada [...] para que se tenha acesso à realidade profunda dos interesses e dos conflitos de classes" (Idem).

Assim, a receita de Boito Jr. para a boa análise política não é, e nesse ponto nem pretende ser, uma novidade, mas apenas a reiteração de uma velha fórmula acrescida de um termo novo: basta investigar os interesses socioeconômicos essenciais de cada classe e fração de classe e então projetá-los na "cena". Diríamos que a fórmula junto com o termo até poderiam conter algo de inovador, se a idéia de cena fosse mesmo levada a sério. Esta, porém, em vez de um bom ponto de partida para o estudo de atores de carne e osso no palco da representação política, acaba sendo apenas a imagem de um teatro de marionetes. Como vimos, só não é inteiramente assim porque o essencialismo permite identificar certos atores, e apenas esses, que afinal não "encenam", mas são o que parecem ser. Esses são os atores que, graças a um vínculo explícito que logram (?) fazer com sua base socioeco- nômica, expressam os interesses da classe que não têm por que produzir disfarces. "Para Marx, os critérios para analisar a cena política não são os mesmos que se devem utilizar na análise dos partidos operários. A opacidade da cena política pode ser superada [...]. Os partidos do proletariado, para representar os interesses dessa classe, necessitam fazê-lo abertamente. A sua relação de representação exclui qualquer relação de dissimulação. Ao proceder assim [?], os partidos operários lançam uma luz nova sobre o conjunto da cena política. Fazem com que cada partido apareça, aos olhos do operariado organizado, como aquilo que ele realmente é, a despeito do trabalho de ideologia que encobre os interesses profundos de cada partido e de cada corrente política burguesa e pequenoburguesa" (p. 151). No fundo, a autêntica análise científica só pode estar a serviço dos interesses dessa classe e dos partidos dessa classe, já que todos os três - classe, partido da classe e cientista social dotado do instrumental adequado -, de maneiras distintas, coincidem naquilo que os tornam portadores da verdade social.

Mas que verdade é essa? A pergunta nos faz ingressar no tema da revolução, objeto explicito de alguns dos ensaios, mas que percorre quase todo o livro. Tendo o autor clara percepção de seu desgaste no debate acadêmico contemporâneo, talvez pudéssemos nos espantar com a insistência no assunto. Simples curiosidade histórica, lip service a um certo público ainda atraído por ela? Não se trata disso: a questão da revolução, tal como entendida pelo autor, é parte intrínseca de sua abordagem.

$\mathrm{O}$ autor faz mais do que esclarecer por que as revoluções aconteceram antes, e por que deixam de acontecer hoje. Ele também indica por que elas poderão voltar a ocorrer no futuro. Impossível percorrer aqui toda a sinuosa análise histórica presente no livro, que em certos momentos até se vale de pesquisas sérias - para discutir a revolução francesa, a Comuna de Paris etc -, embora muito seletivas. Mas é claro que a "ambição" a que Boito Jr. se refere no início do livro não é a de um historiador: todo o seu zelo com a substância histórica, em particular com a das revoluções, tem por trás uma motivação teórica. Qual? As transições, na modernidade, de um modo de produção para outro. A revolução política encontra seu lugar fundamental nesse ponto porque, a seu ver, só ela seria capaz de completar essas transições. A mensagem de fundo, 
aqui, não é simplesmente que as revoluções não são inevitáveis, mas que as próprias transições não o seriam, a não ser por meio de atos políticos, deliberados, de grande envergadura, que varressem, no plano da superestrutura estatal, os empecilhos ao pleno desenvolvimento das novas relações de produção e, por conseguinte, das forças produtivas.

Essa afirmação, por suposto válida especialmente para a transição do capitalismo ao socialismo, deveria ser submetida à prova nas transições próprias das revoluções burguesas - e é só para mostrar isso que o debate sobre o caráter "feudal" ou não do Estado absolutista lhe interessa. Contudo, a despeito do esforço de dar conta das informações históricas, é difícil não notar que aquelas convicções prévias terminam falando por cima das conclusões bem mais ambíguas que poderiam ser extraídas da análise do próprio material utilizado ambigüidade que provavelmente aumentaria, se um material menos restrito, e mais atual, fosse mobilizado. Nada contra o uso de esquemas que apresentem os tipos de Estado - escravista antigo, feudal, capitalista etc. - numa seqüência histórica ideal e então compará-los. Isso, desde que tenhamos claro sua natureza heurística, a nos guiar na aproximação às informações variadíssimas e não raro contraditórias à espera da análise; desde que, em suma, não resvalemos para a substancialização. Mais do que a tese sobre o seu caráter "feudal", o que é notável no trabalho de Perry Anderson sobre os Estados absolutistas, que Boito Jr. cita elogiosamente mas não discute, é a percepção das nuanças: mesmo que não concordemos com a tese principal, e deixemos de lado as disputas entre os marxistas, resta a riqueza da análise e o leve traço da ambigüidade. No ensaio de Boito Jr., vão-se as nunças e ficam os esquemas, que viram "coisas", e todo o material disponível acaba tendo de caber no leito apertado de suas convicções preestabelecidas.

Mas tendo em vista a batalha travada pelo autor contra seus adversários "economicistas", esse tipo de argumento não deixa de fazer sentido. Tomemos, por exemplo, o ensaio sobre "crise revolucionária". Naquele preciosismo que é peculiar, nesse caso, à teoria revolucionária, o fenômeno é circunscrito a tantas peculiaridades, que nos deixa a ponto de imaginar que só mesmo um oráculo, ou quase, para antecipar sua ocorrência. Lançar mão dos pensamentos do camarada Mao Tsetung, e considerar seu escrito Sobre a contradição uma obra sumamente relevante para compreender o assunto (p. 111), pode parecer um pouco exagerado. Mas não se, novamente, compreendermos a fascinação do autor pelo essencialismo. Pois ele está se referindo a um pequeno tratado metafísico-político que visa a um raio $\mathrm{x}$ de toda a realidade, incluindo "o universo físico", mesmo com a ressalva de que "é na sociedade e na mudança política que Mao Tsetung concentra a sua reflexão". Isto é, ele fala de alguém que está vendo, por trás da superficíe das aparências, a "realidade profunda" do desenvolvimento histórico. E não é à toa que tenha sido um líder revolucionário. A revolução, assim como a chave da realidade, é um tesouro muito bem escondido.

Contudo, faz parte da "psicologia" do essencialismo, que é também a psicologia do revolucionário, a angustiante expectativa de que a verdade das coisas, posse de um pequeno grupo durante um tempo que pode ser longo ou não, venha a se tornar um dia uma posse coletiva, um clarão que finalmente imponha a transparência no lugar da opacidade, fazendo com que as contradições sociais se escancarem, as ilusões sejam perdidas e as máscaras caiam. Esse é o tempo da revolução. Mais uma vez não devemos nos surpreender que, num dos últimos ensaios, depois de sugerir que as revoluções do século XX não foram propriamente socialistas (a soviética e a chinesa, apenas nas suas "primeiras fases"), mas um acerto de contas com um passado basicamente pré-capitalista - e, por conseguinte, que o socialismo ainda não foi realmente submetido a teste algum -, o livro comece a traçar um quadro sombrio das condições atuais das massas trabalhadoras e pobres, e da "degradação socioeconômica" de "amplos setores das classes médias", prenunciadoras de "contradições novas" e do aguçamento de "velhas contradições não resolvidas" do capitalismo; e então conclua afirmando: "No século XXI, ao contrário do que ocorreu no século XX, o socialismo poderá colocar-se como objetivo prático para um grande número de revoluções" (p. 221). Poderíamos perguntar: por que não rebeliões, explosões sociais, guerras civis etc., enfim, energias dissipadas, como tantas que a história da humanidade já conheceu e ainda conhece, em vez de revoluçoes? Ou por que não algo menos cataclísmico, um pouco pior ou um pouco melhor do que se vê agora? Porém, longe do autor falar em termos de "pior" ou "melhor": a idéia de revolução 
não é sobre essas coisas miúdas ou medianas, mas sobre opções extremas: reconstrução total ou destruição total, "socialismo ou barbárie". Do contrário, a realidade profunda não poderia ficar tão clara para todos, como o próprio revolucionário o exige. Contudo, em vez de ficar agourando a destruição, Boito Jr. prefere anunciar que, depois de tantas desgraças se abaterem sobre os explorados e os injustiçados, haverá de surgir a oportunidade do grande acerto de contas que exterminará o sistema causador de tais desgraças: é isso o que significa o socialismo, não importa o que venha a ser efetivamente. Mas isso também significa que não estamos mais exatamente na ordem de uma previsão racional, feita para concordar ou discordar. $\mathrm{O}$ registro é outro: em seu estilo tranqüilo e discreto, Armando Boito Jr. oferece-nos na verdade um grande alento, uma mensagem de alta esperança. E assim ficamos com um desconcerto final: podemos desconfiar da mensagem, mas ela já está para além da crítica.

CICERO ARAUJO

é professor do Departamento de Ciência Política da FFLCH/USP. E-mail: craraujo@usp.br.

\section{Do privado ao público na política brasileira}

Moacyr PALMEIRA e César BARREIRA (orgs.). Política no Brasil: visões de antropólogos. Rio de Janeiro, Relume Dumará, 2006. 449 páginas.

\section{Celi Regina Jardim Pinto}

Uma coletânea é sempre muito bem-vinda, mas muitas vezes nos defrontamos com uma coleção de textos que, independentemente da qualidade de seus autores, não constitui um todo que conduz ao diálogo intertextual.

Característica de uma boa coletânea é, portanto, a unidade organizadora no que pese seus inúmeros temas. Politica no Brasil: visões de antropólogos, livro corajoso, composto em 449 páginas, cinco partes e dezoito capítulos, atinge com eficiência as premissas de uma boa coletânea. Com uma formidável unidade, o leitor vislumbra o olhar que norteia a totalidade dos artigos, sem que seja preciso explicitar a cada página as teorias metodológicas do trabalho. Nota-se claramente um grupo de pesquisadores articulados, pensando juntos. Apesar da diversidade temática, os textos dialogam entre si, mostrando como a vida política no país é construída pelas relações estabelecidas no espaço público da política. A idéia é analisar de que maneira a esfera pública mantém relação com o mundo privado e o quanto os compromissos entre essas esferas se confundem, seja entre as famílias, seja no processo constitutivo de carreiras políticas, em que se explicitam a procura e o encontro de eleitores.

Os indivíduos, as relações de poder, a questão de classe, do privado e da trama não expressada nas instituições, mas que chega a elas já formatadas em cargos públicos, são, para os autores, aspectos relevantes a serem tratados nos estudos sobre a política. É importante, pois, que se analise toda a rede de relações que envolve a questão política sob a superfície codificada das instituições políticas.

O livro como um todo induz a uma leitura linear, pois a partir de questões gerais, levantadas na primeira parte, "Democracia, justiça e cidadania", chega-se a questões bem especificas, analisadas na última parte, intitulada "Eventos e politização das relações sociais". Esta trajetória garante à coletânea 